grünblau sein, mit vollkommen ovalen Flügeldecken und lebt in der Ebene (Lenkoran); es kann also nicht in Betracht kommen. Herrn Zolotarew danke ich für die Überlassung dreier Stücke für meine Sammlung.

Bei dieser Gelegenheit sei auch meine Ansicht über $B$. Zolotarewi Rttr. (Wiener Ent. Zeit. 1910, XXIX., 313) ausgesprochen. Beide von mir untersuchten Typen gehören nach der Skulptur des Kopfes und des Halsschildes in die Nähe des B. decorum-siculum und nicht in das Subgenus Pseudolimnaeum.

\title{
Über die mir bekannten Varietäten von Phytodecta (Spartophila) pallida Lin.
}

Von Edm. Reitter in Paskau (Mähren).

Einfarbig gelbrot: Spartophila pallida Lin.: Stammform. Unterseite schwarz:

1. Oberseite gelbrot, ein verkürztes Querband auf der hinteren Hälfte des Halsschildes oder zwei größere Flecken schwarz. Lappland.

a. nigrobasalis $n$.

2. Oberseite gelbrot, ein großer gemeinschaftlicher Fleck hinter der Basis der Flügeldecken schwarz. - Lappland.

\section{a. fuscidorsis $n$.}

3. Oberseite gelbrot, einige Makeln auf den Flügeldecken schwarz. a. decipiens Wse.

4. Oberseite gelbrot, zwei Makeln am Halsschilde und mehrere zusammengeflossene auf den Flügeldecken schwarz.

a. borealis Oliv.

5. Oberseite gelbrot, Flügeldecken schwarz. - Styria.

a. nigripennis Wse.

6. Oberseite gelbrot, Halsschild und Schildchen schwarz. - Lappland.

a. nigrithorax $n$.

7. Oberseite schwarz, der Kopf rostrot, die Flügeldecken an der Spitze im weiten Umfange rostgelb. - Lappland.

\section{a. erythrura n.}

8. Oberseite schwarz, der Kopf, die Basis der Fühler und die Beine ganz oder teilweise gelbrot. - Lapponia.

a. frontalis Oliv.

9. Körper ganz schwarz, nur die Fühlerbasis und der Mund rot. - Tatra.

a. nigricolor $\mathrm{n}$. 


\section{$2 \mathrm{BHL}$ Biodiversity Heritage Library}

Reitter, Edmund. 1914. "Über die mir bekannten Varietäten von Phytodecta (Spartophila) pallida LIN." Wiener entomologische Zeitung 33, 46. https://doi.org/10.5962/bhl.part.17777.

View This Item Online: $\underline{\text { https://www.biodiversitylibrary.org/item/42670 }}$

DOI: https://doi.org/10.5962/bhl.part.17777

Permalink: https://www.biodiversitylibrary.org/partpdf/17777

\section{Holding Institution}

Smithsonian Libraries

\section{Sponsored by}

Smithsonian

\section{Copyright \& Reuse}

Copyright Status: NOT_IN_COPYRIGHT

This document was created from content at the Biodiversity Heritage Library, the world's largest open access digital library for biodiversity literature and archives. Visit BHL at https://www.biodiversitylibrary.org. 